\title{
Prediction Markets in the Laboratory
}

$\begin{array}{lc}\text { Cary Deck } & \text { David Porter } \\ \text { University of Arkansas } & \text { Chapman University } \\ \text { \& Chapman University } & \end{array}$

The idea that there is wisdom from the collective has been forcefully described in "The Wisdom of the Crowds" by James Surowiecki, who argues that the aggregation of information in groups results in better decisions than those that are afforded by any single member of the group. Markets, like opinion polls, are one mechanism for aggregating disparate pieces of information. The aggregation properties of prices were first noted by Hayek (1945) and were formally examined by Muth (1961). In particular, Hayek argues that market prices serve the purpose of sharing and coordinating local and personal knowledge, while Muth shows that markets do not waste information and that the current price contains all the information available from market participants. $^{1}$

Essentially, markets are information processors, taking the "wisdom" from the "crowd" of traders and distilling it into a price. In a famous paper, Roll (1984) examines the market for concentrated orange juice. He found that $98 \%$ of concentrated orange juice production takes

\footnotetext{
${ }^{1}$ Fama's 1970 article provides strong empirical support for this efficient market hypothesis, i.e., security markets are extremely efficient in reflecting the complete and accurate information about the fundamental asset value.
} 
place in central Florida and its value is directly related to cold weather in the region. Roll examined futures contract prices for concentrated orange juice and found that if the closing futures price is higher than its opening price, a more accurate prediction of a freeze can be made by adjusting downward the National Weather Service's temperature forecast.

Prediction markets are special case of asset markets (see Noussair and Tucker this issue for a discussion) where the value of the traded asset is contingent upon the outcome of some uncertain event at or before some prespecified point in time and not upon a claim to some underlying asset as in a futures market for orange juice. In more concrete terms, suppose there is an asset that will pay $\$ 0$ if event $A$ occurs, $\$ 2$ if event $B$ occurs and $\$ 3$ if event $C$ occurs. If some traders have certain information that event A will not occur and other traders have certain information that event B will not occur, then if they pooled (aggregated) their information they would know that event $C$ is a certainty and the asset should be worth $\$ 3$. The question is whether a market in which such an asset was trading would arrive at the $\$ 3$ price, thus effectively aggregating the information and letting everyone know that event $\mathrm{C}$ will occur.

One of the most well-known and well-studied prediction markets is the lowa Electronic Market for US Presidential Elections. In this market a trader can pay $\$ 1$ to purchase a pair of shares. Essentially, one share pays $\$ 1$ if the Democratic candidate wins the popular vote in the US next presidential election and $\$ 0$ otherwise. The other share has a similar payoff structure for the Republican candidate. ${ }^{2}$ At the time this is being written the market price for the democrat

\footnotetext{
${ }^{2}$ Technically, the shares payoff if that party's candidate receives the majority of the votes cast for one of those two parties. That is votes for other parties are not considered. The lowa Electronic Market also operates markets for the vote share in US presidential elections as well as markets for Congressional election outcomes and stated Federal Reserve Policies.
} 
share is 0.60 indicating a $60 \%$ chance that the democratic candidate, Barak Obama, will receive the majority of the popular vote in the 2012 election. Over the last several presidential election cycles, the lowa Electronic Market has been found to outperform more traditional means of aggregating opinions of candidates such as opinion polls (Berg, et al. 2003). In particular, they examine national polls for the 1988 through 2004 U.S. Presidential elections versus synchronous vote share market prices. The result of the exercise finds that over 964 polls during this time period, the market is closer to the eventual outcome $74 \%$ of the time in the vote share markets (see Figure 1, which is taken from Arrow, et al. 2008). Similar exercises have been carried out by Wolfers and Leigh (2002) for local elections in Australia and Pennock et al. (2001) for box office receipts in the Hollywood Exchange ${ }^{3}$ and both document the relative accuracy of prediction markets.

Figure 1: IEM Prediction Market Accuracies (from Arrow2008)

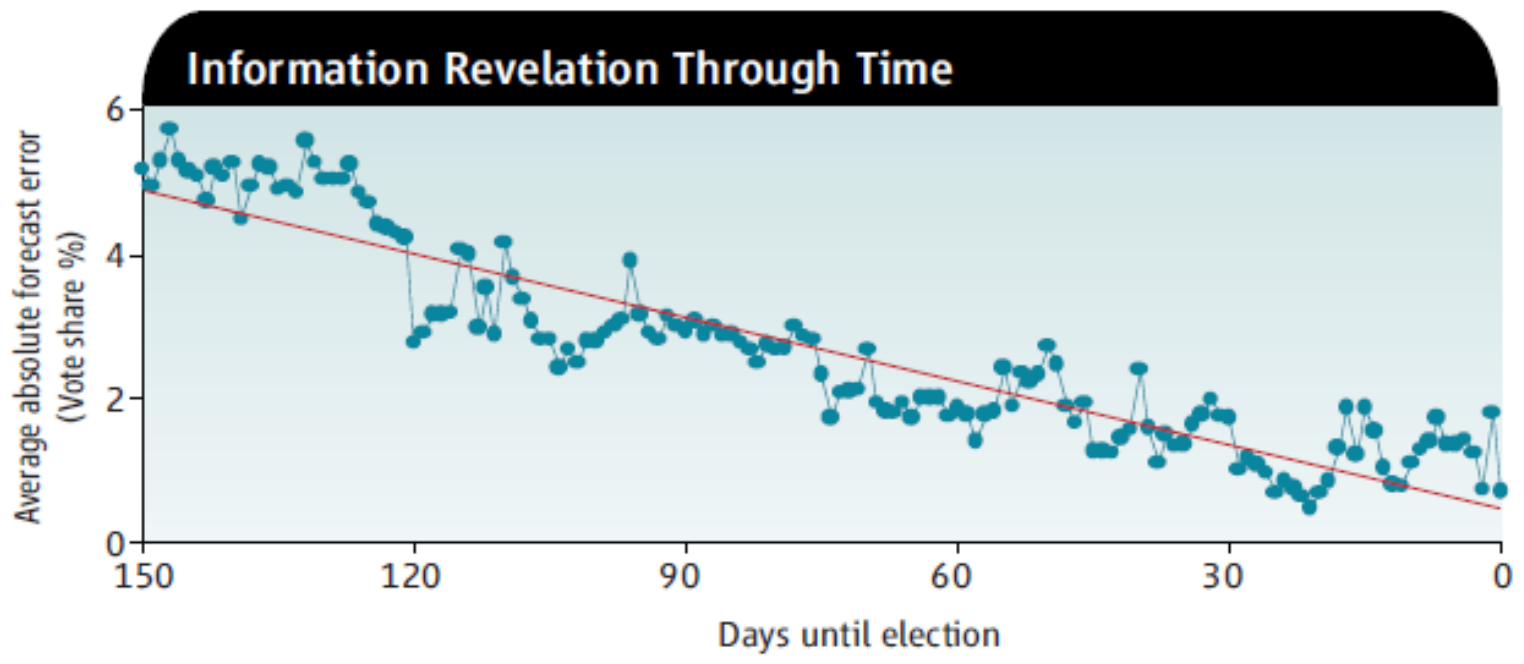

\footnotetext{
${ }^{3}$ The Hollywood Exchange uses artificial currency in its market.
} 
Prediction markets are now used in a wide variety of settings. In particular, many firms have begun experimenting with internal prediction markets to gauge forecasts of events important to the firm. For example, Chen and Plott (2002) developed prediction markets for HewlettPackard Corporation (HP) to forecast sales of products (monthly dollar sales or units sold, three months in the future). There were between 20 to 30 market participants who were firm employees in marketing and finance. They found that the market prices outperformed official HP forecasts. Google has been using prediction market on a large scale since 2005 with its employees. Participants in the Google markets are given an amount of artificial currency ("Goobles") to buy and sell "securities" in specific events that pays off in Goobles. The markets were designed to forecast product launch dates, new office openings, and many other items of strategic importance to Google. Cowgill (2009) found that the while Google markets were reasonably good at predicting events, there was a tendency towards optimism. In addition, this optimism was even more pronounced on days in which Google stock did well. Other companies are now starting to experiment with prediction markets for their own forecasting elements.

The largest public prediction market in the world is Intrade.com and it offers contracts on scientific discoveries, the economy, current events, and geo-political relationships. Prediction markets have even been used to forecast outbreaks of contagious diseases (Polgreen, et al. 2007) and the number of cattle being brought to slaughter (Gallardo 2009). Despite their widespread usage, existing prediction markets cover only a fraction of the domain in which such markets could be used to extract information. Hahn and Tetlock (2005) argue for prediction markets to be used for setting monetary policy. After the terrorist attacks of 
September 2001, a proposal was developed by the Defense Advanced Research Projects Agency to create a Policy Analysis Market (PAM) for the purpose of using prediction markets to identify likely threats to US security and deploy resources accordingly. In 2008, a group of prominent economist wrote in Science about the promise of prediction markets and called for reducing the legal constraints on these markets in the U.S. to harness their power for a variety of uses (See Arrow, et al. 2008).

One of the main obstacles to the implementation of prediction markets, other than concerns about running afoul of gambling laws, is concern about the degree to which they can be manipulated. Setting Federal Reserve Bank policy or National Security policy with systems that can be manipulated is clearly problematic. However, previous attempts to manipulate existing markets have been largely unsuccessful at creating nontransitory price movement: "The profit motive has usually proven sufficient to ensure that attempts at manipulating these [prediction] markets were unsuccessful." (Wolfers and Zitsewitz, 2004, p. 119). Wolfers and Leigh (2002) discuss failed attempts by political candidates to manipulate markets predicting their own success. ${ }^{4}$ Also looking at political prediction markets, Rhode and Strumph (2009, p. 37) conclude that "In almost every speculative attack, prices experienced measurable initial changes. However, these movements were quickly reversed and prices returned close to their previous levels."

In order for the prices in a prediction market to aggregate information there has to be a relationship between prices and traders beliefs. From a theoretical perspective there can be a divergence between mean beliefs and the equilibrium price (see Manski 2006). This divergence

\footnotetext{
${ }^{4}$ Hansen, et al. (2004) were able to manipulate election predictions, but only temporarily.
} 
is tempered when traders are risk averse (see Gjerstad 2005). In this paper we see the ability of prediction markets to aggregate information or be manipulated as an empirical question and as such our focus is on the results from laboratory experiments. ${ }^{5}$

\section{The Success of Markets Aggregating Information}

Plott and Sunder (1988) introduced what has become the classic information aggregation experiment. Like many previous experiments up to that point, their market used a double auction mechanism due to the demonstrated success this institution had in other environments and the dynamic opportunity for traders to adjust their behavior as bids and asks entered the market (as opposed to the static nature of institutions such as a sealed bid offer market where a trader could not update his choices based upon feedback from the market within the period). The traders were all endowed with a large amount of cash and a fixed number of shares. So that profits were tied only to trading and asset dividends, the cash was treated as a loan which had to be repaid at the end of trading. Shares paid dividends to whoever held them when trading was done, but the dividend amount depended upon which of three possible states of the world (denoted $\mathrm{X}, \mathrm{Y}$, and $\mathrm{Z}$ ) was realized and the type of the trader who held the asset (with type being defined by state dependent dividend payoff structure). Prior to trading, Plott and Sunder (1988) drew a ball from a bingo cage to determine the state of the world where the likelihood of each state being drawn was common information among the traders. ${ }^{6}$ However,

\footnotetext{
${ }^{5}$ For a more general review of prediction markets, see Tziralis and Tatsiopoulos (2007).

${ }^{6}$ Smith (1994) makes a distinction between common information, when data are available to everyone, from common knowledge, which involves knowing that everyone knows the information, knowing that everyone knows the information, and knowing that everyone knows that everyone knows the information, and so on. It is one thing for everyone to know that a stock market bubble is about to burst; it is another to know that everyone else knows it is about to burst.
} 
traders were not informed of the realization; instead each trader was told one of the two states that was not drawn. If, for example, the state was $X$, then half of the traders were told the state was not $Y$ and the other half were told that the state was not $Z$. Thus, in aggregate the market participants knew the outcome, but no individual trader knew it. Each experimental session involved multiple sequential markets with endowments, shares, and state drawings being reinitialized before each market in the session.

In total, Plott and Sunder (1988) report the results of 11 sessions totaling 175 markets, each somewhat different from the others including the school from which the subjects were recruited, the number of trader types, the dividend values for each type, the number of traders, endowments, and shares as well as the experience level of the subjects, the duration of the experiment, and whether or not short sales were allowed. ${ }^{7}$ This heterogeneity in the experimental design makes it somewhat difficult to identify the specific effects of any particular aspect of the market, but the researchers classify the markets into three series. In series $A$, there was only a single class of asset and there were always multiple types of traders. A rational for having multiple types is that trading should occur in equilibrium as shares are moved from those who value them least to those who value them most. If everyone had the same value for the shares, then there may be little incentive for any trading to occur. For these series $A$ markets, Plott and Sunder (1988) find that information is not well aggregated and efficiency is lower than the rational expectation model would predict. However, they do find

\footnotetext{
${ }^{7}$ In this experiment, when short sales were allowed, traders had to subsequently buy shares in order to cover the short sales or had to pay an extremely large penalty.
} 
that the allocations and profits are generally consistent with the rational expectations model in the last occurrence of a particular dividend state.

Plott and Sunder (1988) find stronger support for the rational expectations model in their two other sets of markets. In series $B$ the assets are state contingent. Thus rather than trading a single asset that pays off one of three possible dividend amounts, subjects are trading three assets, each of which payoff in a single state. For example, the $\mathrm{X}$ asset pays a positive dividend in state $X$, but does not have a payoff in states $Y$ or $Z$. In series $C$ there is only a single type of trader. That both of these sets of markets produce results that are generally consistent with rational expectations and have prices that reflect aggregated information are important for prediction markets, because most such markets operate with both state dependent assets and a uniform dividend structure.

"Success" in these and other laboratory markets is defined by the rational expectations model, where all of the information is aggregated into the market price, outperforming more myopic models. This should not be construed to mean that all trades occur at the price level that reflects all of the disparate information held by the traders. Indeed, when trading begins there is only private information and it takes time and trading activity for bids, asks, and contracts to reflect more than a trader's private information. For this reason, one would expect prices to move towards the full information level during the course of trading. Thus, researchers typically focus on closing prices rather than starting or average prices. The starting location and speed of convergence likely depend on a wide variety of factors from the distribution of information to the risk attitudes of the traders. Further, market prices are likely to experience 
variability and often do not obtain the theoretically predicted price even at the end of the trading horizon, a fact that may be lost in some of the rhetoric of prediction markets. Figure 2 shows the observed behavior in one of the series $C$ sessions, where one can clearly see these behavioral patterns. This figure plots contract prices over the course of the experiment blocked by market period with the true state shown in parenthesis and the average price given above the chart. The thick / dashed / dotted lines denote the Rational Expectations / Prior Information / Maximin model price predictions. ${ }^{8}$

Figure 2. Market 7 from Plott and Sunder (1988)

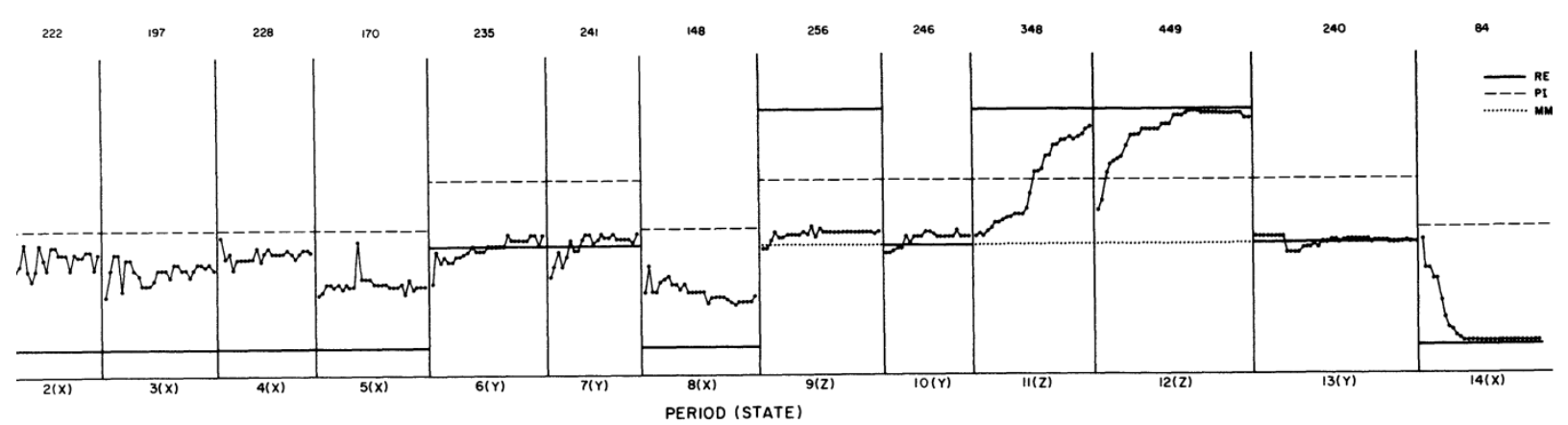

Noting that Plott and Sunder's (1988) success had come when the market involved a complete set of contingent claims or when preferences were identical, Forsythe and Lundholm (1990) set out to identify conditions under which a single security would obtain the price predicted by the rational expectations model when traders had diverse preferences. As such Forsythe and Lundholm (1990) closely follow Plot and Sunder (1988) in most respects (endowments of cash and shares, no short sales, double auction, etc.). They conducted two sets of experiments:

\footnotetext{
${ }^{8}$ The prior Information model assumes that traders update their beliefs after observing the private signal according to Bayes rule and act upon this probability to maximize their expected payoff. The maximin model assumes that traders will not purchase an asset unless the price is below the minimum possible value the trader knows the asset could take with certainty.
} 
what they call "better chance" and what one might call more challenging. As the name indicates the better chance markets "were designed to give the (Rational Expectations) model a better chance for success..." (p. 311). In these markets, the two dividend structures were common information, unlike in the prior study. Also unlike the prior study, subjects gained experience by participating with the same group on two different days with everyone switching dividend structures on the second day. ${ }^{9}$

By and large, by the end of the first day (12 to 15 market periods) trading did not successfully aggregate information as observed prices varied little with the true state. By the second day behavior did conform to the rational expectations model, at least for closing prices in the last few market periods. However, earlier on the second day closing prices are often better described by a private information model. For example in "Market 4" with experienced traders, shown in Figure 2, the prior information model outperforms the rational expectations model in periods $1,4,10,11,12,13,14,16,17$, and 18 . Had this session only lasted 17 periods like the other three once experienced better chance markets, the authors would not have been able to tout the success of the rational expectations model "by the last occurrence of each state" in all these sessions. Again, when information aggregation occurs in the market, it does so through trading so the initial prices are based upon private information and other idiosyncratic aspects

\footnotetext{
${ }^{9}$ Of course there were several other differences as well including intentional ones such as the use of a mechanized device to select the true state each period and unintentional ones such as the subject pools (in this case MBA and undergraduate students at a different school). This second point is not meant as a criticism, but as a reminder that pure replication is never possible. Things like the room temperature, the gender of the researcher, or the time of day are not normally reported in experiments, but any of these features could add variation in observed behavior. Thus, it is important for a wider variety of researchers to conduct similar variations of important results and that one should be cautious with regards to any single study, but can feel comfortable with results that are shown to be robust. Thus, the similarity in the results between Plott and Sunder (1988) and the inexperienced subjects in Forsythe and Lundholm (1990) better chance markets despite the slight variations gives greater confidence in the reliability of the behavior.
} 
of the traders. During a market period prices tend to move from a common starting point towards the rational expectations price conditional on the true state. Casual inspection of the relevant figures in Forsythe and Lundholm (1990) reveal that the speed of convergence within a period varies wildly, but often the average price and the closing price are not close, see Figure 3. In this figure the legend is the same as in Figure 2, but trading volume and total efficiency by period have been added to the top of the chart.

Figure 3. Market 4 from Forsythe and Lundholm (1990)

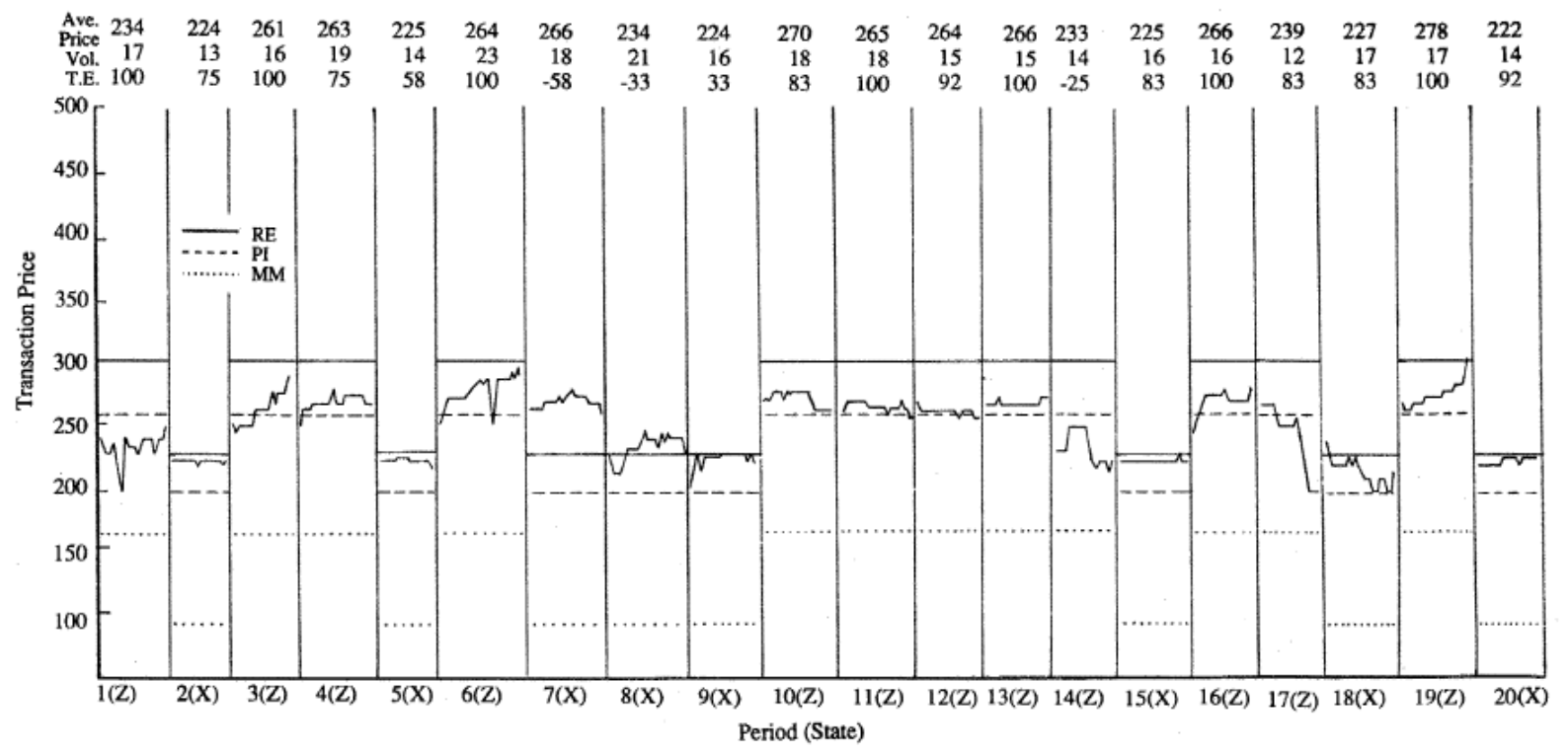

From the better chance markets the authors conclude that experience, common knowledge of the dividend structure and of trader types, and relatively thick markets are sufficient for the rational expectations predictions to be accurate. Experience took two forms in the better chance markets: one was familiarity with the trading institution and market operations and the other was having participated as a trader with the alternative dividend structure. To explore this last feature the authors conducted some "constant type" experiments where the traders 
retained the same dividend structure both days, but still had common information regarding both dividend structures. The results were similar to the better chance markets and the authors conclude that switching types is not necessary for convergence.

Forsythe and Lundholm (1990) also conducted a series of experiments where they removed the common information about dividends so that a trader only knows his or her own private payoff for each state. In these "no common knowledge" treatment market prices do not reflect information aggregation indicating that common dividend information is necessary. Fortunately for advocates of prediction markets the traded assets pay the same dividend to everyone and thus the dividend structure is common information. Additionally, Forsythe and Lundholm (1990) conducted "experience and random type" sessions where subjects were twice experienced having participated in one of the pairs of better chance sessions and where the dividend type was randomly assigned in each market. In these cases, closing prices again converged to the rational expectations predictions by the end session, but average prices throughout the day and closing prices in early markets did not. From this, the authors conclude that repeated experience with the same people and a fixed dividend structure are not necessary for the success of the rational expectations model. The former is important for prediction markets given the way they are normally operationalized in practice.

More recently, Bodsky (2012) considers the case where two states of the world are possible, but traders only observe a noisy signal of the true state. In these experiments, subjects were shown two distributions of marbles, which were deposited into identical bags. One of the bags was then randomly selected and subjects had to predict which one had been chosen. Subjects 
were endowed with cash and shares of two types of contingent assets, one for each possible bag that could have been selected. Each subject privately observed a single draw from the selected bag and could trade with the other participants based upon this private information. This process was repeated so that each subject ultimately observed several draws from the selected bag. ${ }^{10}$ Subjects were also asked to state their subjective probabilistic belief about which bag had been drawn. Bodsky (2012) found considerable variation in behavior, with most, but not all sessions pricing the assets near the Bayesian predictions.

\section{Comparisons of Predication Markets with Other Mechanisms for Information Aggregation}

The demonstrated success and popularity of (double auction) markets for aggregating information has led to it being a standard of comparison for other institutions such as surveys or scoring rules. ${ }^{11}$ Graefe (2010) argues that prediction markets outperform surveys when judgment is needed. However, Rieg and Schoder (2012) find little justification for the use of prediction markets, which may be more costly to operate, in comparison to surveys. They use two lab experiments and an online study. Each experiment compares a double auction, a scoring rule, and a survey. In the two lab experiments, subjects predict the outcomes of soccer games while the researchers vary the diversity of information and do not allow entry/exit nor do they allow users to do research. In the online experiment, entry/exit, information diversity, and information search are not controlled. They find that all of the procedures yield similar accuracy in the lab experiments, a finding similar to earlier work reported in Rieg and Schoder

\footnotetext{
${ }^{10}$ This process is similar to Camerer (1987) except that information was private. The point of the Camerer experiments was to see if the market would correctly price the assets and in general the market price was similar to the price that would be obtained under Bayesian updating.

${ }^{11}$ Chen and Pennock (2010) provide a detailed survey of the various types of institutions for aggregating information.
} 
(2010). However, in the online experiments, they concluded that the market is less accurate, which they attribute in part to difficulty in maintaining ongoing participation in markets. Graefe and Armstrong (2010) also compare prediction markets and surveys as well as other methods such as face-to-face meetings. In addition to finding little evidence that prediction markets outperform other methods of making a forecast, they report that participants were least satisfied with the process when engaging in prediction markets.

Healy, et al. (2012) compare pari-mutuel betting with double auction markets. ${ }^{12}$ They find that in simple environments where there is a single event with a binary state, the double auction performs relatively well even though their markets are very thin involving only three traders. This result is also encouraging for many prediction markets which tend to focus on single events and may operate with relatively small numbers of traders. In their study, subjects observe "several flips" of one of two possible "biased coins" and try to predict the chance that a future flip will be heads. Healy, et al. (2012) also find that in more complicated environments where there are multiple correlated information states the double auction does not perform as well. Instead, they find that the Delphi or iterated poll method is superior not only outperforming the double auction and pari-mutuel betting, but also outperforming the market scoring rule of Hanson (2003). ${ }^{13}$ Of course, these results are all conditional on the very thin three person markets used in the study.

\footnotetext{
${ }^{12}$ Plott, et al (2003) also study pari-mutual betting markets. They find mixed success for these systems in aggregating information as predicted by the rational expectations model.

${ }_{13}$ Blohm, et al. (2012) use experimental markets with scoring rules in a two (single market v multiple market) by three (levels of elasticity) experimental design. They find that multiple markets improve efficiency, but that the impact of a change in elasticity depends on the number of markets and the level of elasticity.
} 
Ledyard, et al. (2009) also looks at cases where there are multiple correlated events. The events were stochastic, e.g. in the simple environment event $X$ occurred with a $70 \%$ chance, $Y$ had a $20 \%$ chance of matching $X$, and $Z$ had a $50 \%$ chance of occurring independently of $X$ and Y. Different subjects observed realizations of different pairs of these stochastic processes but did not know if they were observing $X, Y$ or $Z$. In their most complicated environment there were 8 events (i.e. $2^{8}=256$ possible states). For their double auction markets, traders could trade simple shares for each event, thus in the complicated environment there were 8 markets. ${ }^{14}$ This institution was compared to a combinatorial call market where traders could place bids or asks for single events or combinations of event outcomes. They report that the double auction did not perform well. This result may be due in part to the implementation, but this remains an open question as the authors did not operate a non-combinatorial call market or a combinatorial double auction. The authors also considered scoring rules and opinion polls and found that market scoring performed relatively well in the complicated environment. ${ }^{15}$

Together these papers suggest that prediction markets are not universally the best choice. Rather, it is important to identify when prediction markets are a good choice. The answer depends at least in part on the extent of the robustness of these markets to insiders or manipulators.

\section{How Do Insiders Impact Markets?}

\footnotetext{
${ }^{14}$ There was a single market for each event (event A occurs), rather than two markets ( $A$ occurs and $A$ does not occur) as short sales were allowed.

${ }^{15}$ Klingert and Meyer (2012) use simulations to compare continuous double auctions and market scoring. They conclude that market scoring is preferable. Jian and Sami (2012) investigate two forms of a market scoring rule, one in which people directly state their probabilistic beliefs and one in which traders reveal their beliefs by trading assets with an automated market maker. Ultimately they find that both mechanisms perform equally well.
} 
In another seminal paper, Plott and Sunder (1982) report a series of experiments on a market's ability to disseminate information more so than aggregate it. These markets were similar to those in Plott and Sunder (1988) described above in many respects (endowments of cash and shares, trading via double auction, state and type dependent payoffs, process for determining state). However, what was different was the distribution of information. In four of their five sessions, when a trader received information it perfectly identified the true state that would determine dividends. In the fifth (identified as Market 1 in the paper) informed traders observed a series of signals (draws from the bingo cage) so that they had a noisy signal of the true state. However, each informed trader observed the same set of signals and thus would have the same posterior beliefs from Bayesian updating.

In some market periods of Plott and Sunder (1982) no one received information about the true state, in others only some traders received information and in the remaining markets everyone knew the true state. If a trader has better information then other traders, the informed trader can attempt to exploit this informational advantage, but doing so will reveal (and thus eliminate) the informational advantage. For example, if an individual knows that the price of an asset is too low, then that person should purchase shares in order to take advantage of the situation. In doing so, the trader will bid up the price of the asset until the price reflects this private information. There were several idiosyncrasies across sessions, including an extra possible state in one, fewer traders in another, various numbers of markets in a session, differing patterns of information conditions, and differences in the commonality of information regarding the number of insiders. This heterogeneity again makes it difficult to identify the effects of specific aspects of the experimental design, but in aggregate the results provide 
general support for the rational expectations model in terms of prices, allocations, efficiency, and profits. Thus, the information that insiders possess is disseminated through the market trading process. ${ }^{16}$

Banks (1985) noted that Plott and Sunder (1982) did not vary the identity of the informed traders leading open the possibility that uniformed traders had simply learned who to follow rather than the market having aggregated information. To separate this explanation from the one preferred by Plott and Sunder (1982), Banks replicated their design except that the identity of the informed traders was randomized each period. The results support the claims of Plott and Sunder with respect to the pricing dynamics, but also indicate that the strength of the results in later periods may have been biased by this feature of the design.

Camerer and Weigelt (1991) also explored a market environment where insiders with perfect information may or may not be present. In most other respects their markets were similar to those previously discussed (traders were endowed with shares and cash, short sales were prohibited, trading via double auction, etc.). Traders knew their own values in each state but not the values of the other traders. In market periods in which there were insiders the identity of those insiders was determined randomly. All of these procedures were common information among the traders. They reported that in markets where insiders were present, the rational expectations model again describes closing prices reasonably well. When there were no insiders, there is no information for the market to aggregate. However, as uninformed traders do not know of the absence of insiders it is possible for them to misinterpret the behavior of

\footnotetext{
${ }^{16}$ Friedman, et al. (1984) introduced a futures market for an asset that endures for three trading periods. They report that futures markets stabilize spot prices and help facilitate the leakage of insider information.
} 
other uniformed traders as revealing insider information. If an uninformed trader acts on such a mistake, this can serve as a signal to other uninformed traders thereby creating an information "mirage." However, sustained mirages were only observed in 4 of the 47 periods where such mirages are possible suggesting that information markets are not very susceptible to this phenomenon, which is good news for the functioning prediction markets.

\section{Manipulation}

In any market, a trader may want to manipulate the price so that he or she can subsequently take advantage of the price. For example, a trader would like to push the price of an asset down so that she could cheaply purchase a large volume, which could be sold at a profit once the price has recovered. Veiga and Vorsatz (2010) find evidence that asset market prices can be manipulated in the short run under certain conditions. In their markets there are both informed and uninformed traders, but each trader's type is private information. Thus, when a robot trader is introduced with the strategy of buying early and selling late regardless of profitability, uninformed traders cannot tell the buying behavior is not being driven by the informed traders. When the asset should have a high price this strategy pushes prices towards the correct level, but when the asset should have a low price this strategy does have a transitory effect. The automated strategy proved profitable, but still Veiga and Vorsatz (2010) report that "The presence of the robot trader does not affect the last contract price significantly." (p. 385.).

Prediction markets also face the danger that a manipulator may successfully alter the price so that policy makers who are using the aggregated information will be misled. Returning to the 
example of the PAM proposed by DARPA, if a terrorist could mislead the Department of Defense about how to allocate resources then such markets are of little value for national security. The same is true for other prediction markets that are taken as inputs to other decision making problems, but the imagery is not as stark.

In a direct test with incentives for manipulation, Hanson et al. (2006) create a laboratory information market in which an asset has three initially equally likely dividends (0, 40 and 100). As in Plott and Sunder (1988), some participants have information that one of the dividends is not available (e.g. "not 40") and other participants have information that another dividend is not available (e.g. "not 0"). Together participants would have full information about the actual outcome. For obvious reasons, they call this their replication treatment (RT). They contrast this condition with a treatment in which there are known manipulators who get rewarded not only on their portfolio outcome but also with a bonus based on the median contract price for the period. The higher the median contract price, the higher the manipulator's bonus in this manipulation treatment (MT). Figure 4 shows the price results of these experiments.

Hanson et al. (2006) find that manipulators submit higher bids than non-manipulators (in line with their incentives), but they have no effect on the information aggregation properties of the market because non-manipulators tend to accept contracts at lower prices. It is these countervailing strategies that stymie manipulation attempts. 
Figure 4. Comparison of Replication Treatment (RT)

and Manipulation Treatment (MT) in Hanson et al (2006)

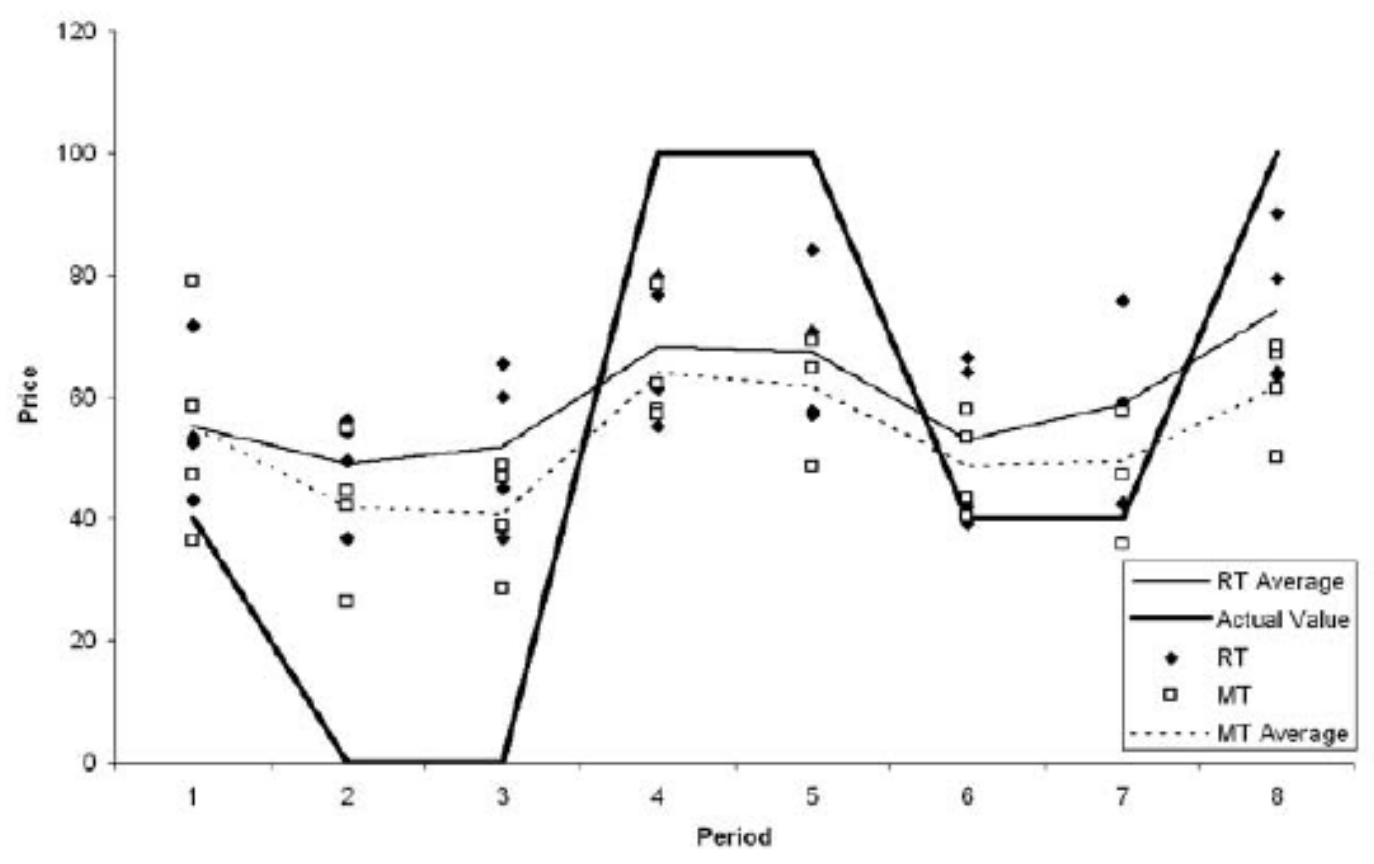

In a follow-up study Oprea et al. (2007) are the first to ask a fundamental question: Can individuals without any specific information about the underlying value of an asset, forecast the actual state by just viewing the contract formation in an information as an outsider? That is, can a policymaker use the information from bids, ask and contracts in an information market to better forecast the actual state, and presumably better allocate his resources, than if he relied only on his (lack of) prior information? To do this, they create an environment in which there are but two states (0 or 100). Each trader receives a signal ( + or - ). If the true state is 0 , participants draw signals (with replacement) from a bag containing $1+$ and 2 - marbles; If the true state is 100, participants draw signals (with replacement) from a bag containing $2+$ and 1 - 
marbles. Armed with this information, participants trade in the market. The Basyesian posterior based on the number of gray signals in the market is provided in Figure 5.

Figure 5. Expected Price conditional on Aggregate Number of + Signals (Oprea et al. 2007)

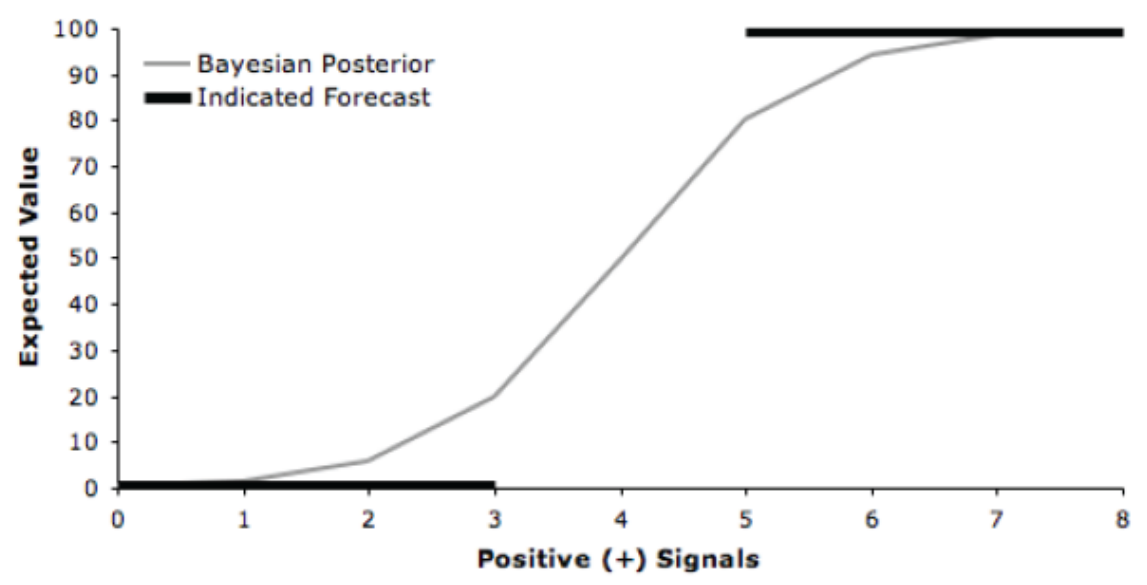

The uninformed outside forecasters in this market are rewarded if they accurately forecast the state after the market closes. The black line in the above figure shows the predicted forecast from a fully informed Bayesian. To this setting, they introduce manipulators who are given a target randomly selected from $\{0,100\}$. The manipulators are rewarded based on both their profits in the market and how far off the average forecast (of the three forecasters) was relative to the manipulator's target. Figure 6 shows how well the forecaster performed on each treatment. They find that manipulators try to manipulate prices, but the forecasts are not impaired. This result is highly encouraging in that forecasters were able to use the market to improve their predictions and that manipulation attempts did not significantly impact this process in a negative way. 
Figure 6. Forecaster Accuracy (Oprea et al. 2007)

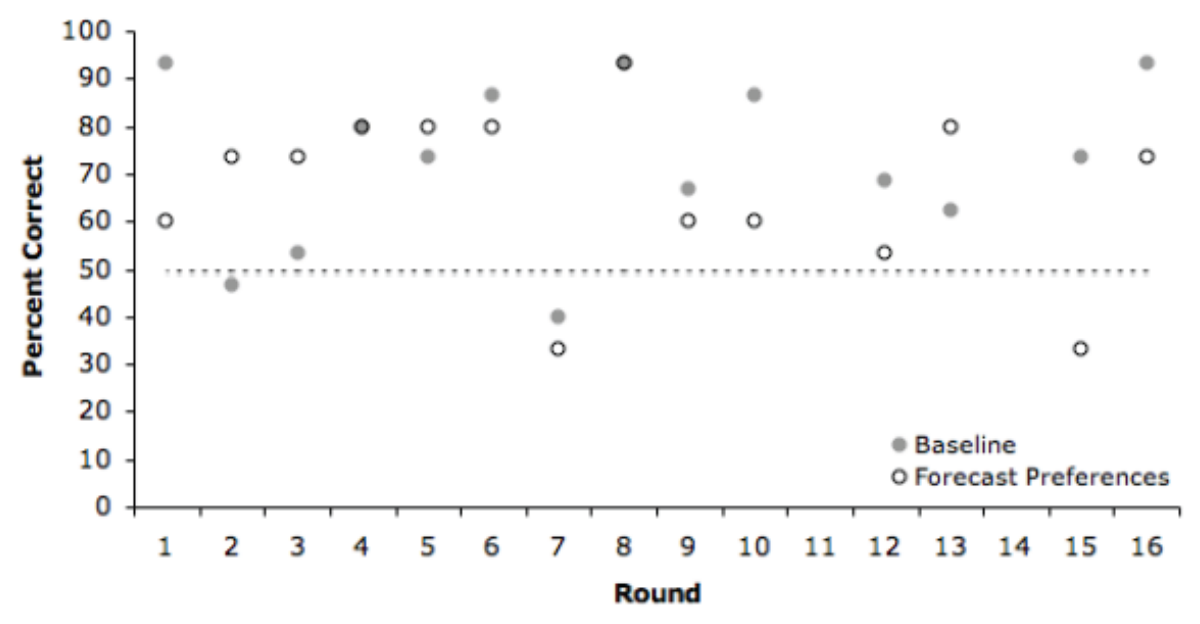

In an attempt to stress test the robustness of this manipulation process, Deck et al. (2012) note that the Oprea et al. design does not measure the intensity of the forecaster's beliefs. Thus, their design has forecasters investing in which state they believe will occur. As payoffs are quadratic, forecasters have a direct incentive to reveal their beliefs. Further, Deck et al. argue that the incentives of the manipulators have been heretofore relatively weak because 1 . rewards from successful manipulation may be offset by losses from trading activities and 2 . with multiple manipulators there is pressure to free rider. To address these two points, at most a single manipulator is active in any period in Deck, et al and the manipulator is only compensated based on how well she fools uninformed forecasters (i.e. manipulators were not paid on their portfolio). Finally, the manipulator is well-heeled so she is not cash constrained. In other respects Deck et al. follows Oprea et al except that traders could create shares by setting aside enough cash to cover the maximum possible dividend payment. In the treatments without manipulators, they affirm the result that forecasters can exploit information in the 
market to make predictions that are better than random guessing. This suggests that fixed supply of shares that has characterized most prediction market studies is not necessary. However, when manipulators are present, the forecasters do not better than random guessing, clearly demonstrating the destructive nature that a manipulator can do with sufficient incentive and wherewithal. Deck et al. do identify a silver lining: manipulators increase trade volume and information can be gleaned from the excess bids or asks in the market. Still, more research is needed to investigate how forecaster, traders, and manipulators might alter their behavior if it is common knowledge that previous work has identified that manipulators increase volume but information remains in the excess bids.

\section{Future Work}

To date, lab experiments have shown that markets do a reasonably good job of aggregating and/or disseminating information. This parallels what has been observed in the field. However, the success of prediction markets should not be construed to mean that in the lab markets provide fully aggregated information during the trading process or always outperform other means of aggregating beliefs. It is not as though prediction markets are a panacea while opinion polls and other methods are no better than random guesses. Rather, prediction markets provide a viable means for harnessing the "wisdom of crowds," at least under certain conditions such as when the number of traders is reasonably thick, the states are not too complex, the payoff structure is relatively simple, and the incentives and wherewithal to manipulate are relatively small. 
Clearly more research is needed to fully understand the conditions under which prediction markets are robust to manipulation attempts if such markets are going to be used as decision making inputs or for the allocation of resources. One obvious gap in the experimental literature is the case where there is heterogeneity among manipulators in terms of the optimal direction they wish to push prices. Another, more critical, gap in the literature concerns the situation in which the state is endogenous or under the control of those who can trade. Again, taking the example of the PAM markets, if the market prices were observable then a terrorist could condition an attack on a low price that indicates a low probability of attack. Of course, this

would make an attack more likely when the price was low, which would drive prices up making an attack less likely which would push prices back down making an attack more likely an so on.

\section{References}

Arrow, Kenneth, Robert Forsythe, Michael Gorham, Robert Hahn, Robin Hanson, John Ledyard, Saul Levmore, Robert Litan, Paul Milgrom, Forrest Nelson, George Neumann, Marco Ottaviani, Thomas Schelling, Robert Shiller, Vernon Smith, Erik Snowberg, Cass Sunstein, Paul Tetlock, Philip Tetlock, Hal Varian, Justin Wolfers, and Eric Zitzewitz (2008): "The Promise of Prediction Markets," Science, 320.

Banks, Jeffrey (1985): “Price-conveyed Information Versus Observed Insider Behavior: A Note on Rational Expectations Convergence," Journal of Political Economy, 93.

Berg, Joyce and Thomas Rietz (2003): “Prediction Markets as Decision Support Systems," Information Systems Frontiers, 5.

Blohm, Ivo, Christoph Riedl, Johann Füller, Orhan Köroglu, Jan Marco Leimeister, and Helmut Krcmar (2012): "The Effects of Prediction Market Design and Price Elasticity on Trading Performance of Users: An Experimental Analysis," CoRR, 1204.3457.

Bodsky, Rachel (2012): “Information Aggregation in Prediction Markets: Experimental Evidence," Master's Thesis, Chapman University.

Camerer, Colin (1987): “Do Biases in Probability Judgment Matter in Markets? Experimental Evidence," The American Economic Review, 77. 
Camerer, Colin and Keith Weigelt (1991): "Information Mirages in Experimental Asset Markets," Journal of Business, 64.

Chen, Kay-Yut and Charlie Plott (2002): "Information Aggregation Mechanisms, Concept, Design and Field Implementation," Social Science Working Paper no. 1131, California Institute of Technology.

Chen, Yiling and David Pennock (2010): “Designing Markets for Prediction,” Al Magazine, 31 (4).

Cowgill, Bo, Justin Wolfers, and Eric Zitzewitz (2008): “Using Prediction Markets to Track Information Flows: Evidence from Google," Working paper. Available at:

http://bocowgill.com/GooglePredictionMarketPaper.pdf

Deck, Cary, Shengle Lin, and Dave Porter (2012): "Affecting Policy by Manipulating Prediction Markets: Experimental Evidence," Working paper. Available at:

http://comp.uark.edu/ cdeck/Affecting\%20Policy\%20by\%20Manipulating\%20Prediction\%20M arkets.pdf

Forsythe, Robert and Russell Lundholm (1990): "Information Aggregation in an Experimental Market," Econometrica, 58.

Friedman, Daniel, Glenn Harrison, and Jon Salmon (1984): "The Informational Efficiency of Experimental Markets," Journal of Political Economy 92.

Gallardo, Paola and Alexandra Heath (2009): "Execution Methods in Foreign Exchange Markets," BIS Quarterly Review. Available at SSRN: http://ssrn.com/abstract=1516369

Gjerstad, Seven (2005): "Risk Aversion, Beliefs, and Prediction Market Equilibrium," Working paper. Available at: https://aea-net.org/assa/2006/0106_1015_0701.pdf

Graefe, Andreas (2010): “Are Prediction Markets More Accurate than Simple Surveys?” Foresight: The International Journal of Applied Forecasting, 19.

Graefe, Andreas and J. Scott Armstrong (2010): "Comparing Face-to-face Meetings, Nominal Groups, Delphi and Prediction Markets on an Estimation Task," International Journal of Forecasting, 27 (1).

Hahn, Robert and Paul Tetlock (2005): “Using Information Markets to Improve Public Decision Making," Harvard Journal of Law and Public Policy, 29.

Hansen, Jan, Carsten Schmidt, and Martin Strobel (2004): "Manipulation in political stock markets - preconditions and evidence," Applied Economics Letters, 11 (7).

Hanson, Robin (2003): “Combinatorial Information Market Design," Information Systems Frontiers, 5 (1). 
Hanson, Robin, Ryan Oprea and David Porter (2006): "Information Aggregation and Manipulation in an Experimental Market," Journal of Economic Behavior and Organization, 60. Hayek, Friedrich (1945): "The Use of Knowledge in Society," American Economic Review, 35. Healy, Paul, Sera Linardi, J. Richard Lowery, and John Ledyard (1996): "Prediction Markets: Alternative Mechanisms for Complex Environments with Few Traders," Management Science, 56.

Jian, Lian and Rahul Sami (2012): “Aggregation and Manipulation in Prediction Markets: Effects of Trading Mechanism and Information Distribution," Management Science, 58 (1).

Klingert, Frank and Matthias Meyer (2012): "Effectively Combining Experimental Economics and Multi-agent Simulation: Suggestions for a Procedural Integration with an Example from Prediction Markets Research," Computational \& Mathematical Organization Theory, 18 (1).

Ledyard, John, Robin Hanson, and Takashi Ishikida (2009): “An Experimental Test of Combinatorial Information Markets, Journal of Economic Behavior and Organization, 69.

Manski, Charles (2006): "Interpreting the Predictions of Prediction Markets," Economics Letters, $91(3)$.

Muth, John (1961): "Rational Expectations and the Theory of Price Movements," Econometrica, 29.

Noussair, Charles and Steven Tucker (2006): "Futures Markets And Bubble Formation In Experimental Asset Markets," Pacific Economic Review, 11 (2).

Oprea, Ryan, David Porter, Chris Hibbert, Robin Hanson, and Dorina Tila (2007): “Can Manipulators Mislead Market Observers?" ESI Working Paper, Chapman University. Available at: http://hanson.gmu.edu/judges.pdf

Pennock, David, Steve Lawrence, C. Lee Giles, and Finn Årup Nielsen (2001): "The Real Power of Artificial Markets," Science, 291 (5506).

Plott, Charles and Shyam Sunder (1982): "Efficiency of Experimental Security Markets with Insider Information: An Application of Rational-Expectations Models," Journal of Political Economy, 90.

Plott, Charles and Shyam Sunder (1988): "Rational Expectations and the Aggregation of Diverse Information in Laboratory Security Markets," Econometrica, 56.

Plott, Charles, Jorgen Wit, and Winston Yang (2003): "Parimutuel Betting Markets as Information Aggregation Devices: Experimental Results," Economic Theory, 22.

Polgreen, Philip, Forrest Nelson, George Neumann, and Robert Weinstein (2007): "Use of Prediction Markets to Forecast Infectious Disease Activity," Clinical Infectious Diseases, 44 (2). 
Rhode, Paul and Koleman Strumph (2009): "Historical Presidential Betting Markets," Journal of Economic Perspectives, 18 (2).

Rieg, Robert and Ramona Schoder (2010): “Forecasting Accuracy: Comparing Prediction Markets and Surveys - An Experimental Study," The Journal of Prediction Markets, 4 (3).

Rieg, Robert and Ramona Schoder (2012): “Averaging and Private Information as Drivers of Prediction Market Accuracy: Evidence from Experimental Studies," Available at: http://www.forecasters.org/submissions/RiegRobertISF2011.pdf

Roll, Richard (1984): “Orange Juice and Weather," American Economic Review, 74 (5).

Smith, Vernon (1994): "Economics in the Laboratory," Journal of Economic Perspectives, 8 (1).

Surowiecki James (2004): "The Wisdom of Crowds," Doubleday: New York.

Tziralis, Georgios and Ilias Tatsiopoulos (2007): "Prediction Markets: An Extended Literature Review," Journal of Prediction Markets, 1.

Veiga, Helena and Marc Vorsatz (2010): "Information Aggregation in Experimental Asset Markets in the Presence of a Manipulator," Experimental Economics, 13 (4).

Wolfers, Justin and Andrew Leigh (2002): "Three Tools for Forecasting Federal Elections: Lessons from 2001," Australian Journal of Political Science, 37 (2).

Wolfers, Justin and Eric Zitzewitz (2004): "Prediction Markets," Journal of Economic Perspectives, 18 (2). 
2013

\section{Economic Science Institute Working Papers}

13-04 Corgnet, B., Hernán-Gonzalez, R., Kujal, P., and Porter, D. The Effect of Earned vs. House Money on Price Bubble Formation in Experimental Asset Markets.

13-03 Sheremeta, R. and Zhang, J. Three-Player Trust Game with Insider Communication.

13-02 McCarter, M. and Sheremeta, R. You Can't Put Old Wine in New Bottles: The Effect of Newcomers on Coordination in Groups.

13-01 Corgnet, B., Hernan-Gonzalez, R., and Rassenti, S. Peer Pressure and Moral Hazard in Teams: Experimental Evidence.

\section{2}

12-31 Thomas, C. An Alternating-Offers Model of Multilateral Negotiations.

12-30 Mago, S., Sheremeta, R. and Yates, A. Best-of-Three Contest Experiments: Strategic versus psychological momentum.

12-29 Bigoni, M., Camera, G. and Casari, M. Strategies of Cooperation and Punishment among Students and Clerical Workers.

12-28 Camera, G. and Kim, J. Buyer's Equilibrium with Capacity Constraints and Restricted Mobility: A recursive approach.

12-27 Camera, G., Casari, M., and Bigoni, M. Binding Promises and Cooperation Among Strangers.

12-26 Schniter, E., Shields, T. and Dickhaut, J. Ageism \& Cooperation.

12-25 Gjerstad, S. and Smith, V. Balance Sheet Crises: Causes, Consequences and Responses.

12-24 Gómez-Miñambres, J., Corgnet, B. and Hernán-Gonzalez, R. Goal Setting and Monetary Incentives: When Large Stakes Are Not Enough.

12-23 Clots-Figueras, I., Hernán González, R., and Kujal, P. Asymmetry and Deception in the Investment Game.

12-22 Dechenaux, E., Kovenock, D. and Sheremeta, R. A Survey of Experimental Research on Contests, All-Pay Auctions and Tournaments.

12-21 Rubin, J. and Sheremeta, R. Principal-Agent Settings with Random Shocks. 
12-20 Gómez-Miñambres, J. and Schniter, E. Menu-Dependent Emotions and Self-Control.

12-19 Schniter, E., Sheremeta, R., and Sznycer, D. Building and Rebuilding Trust with Promises and Apologies.

12-18 Shields, T. and Xin, B. Higher-order Beliefs in Simple Trading Models.

12-17 Pfeiffer, G. and Shields, T. Performance-Based Compensation and Firm Value: Experimental evidence.

12-16 Kimbrough, E. and Sheremeta, R. Why Can't We Be Friends? Entitlements, bargaining, and conflict.

12-15 Mago, S., Savikhin, A., and Sheremeta, R. Facing Your Opponents: Social identification and information feedback in contests.

12-14 McCarter, M., Kopelman, S., Turk, T. and Ybarra, C. Too Many Cooks Spoil the Broth: How the tragedy of the anticommons emerges in organizations.

12-13 Chowdhury, S., Sheremeta, R. and Turocy, T. Overdissipation and Convergence in Rent-seeking Experiments: Cost structure and prize allocation rules.

12-12 Bodsky, R., Donato, D., James, K. and Porter, D. Experimental Evidence on the Properties of the California's Cap and Trade Price Containment Reserve.

12-11 Branas-Garza, P., Espin, A. and Exadaktylos, F. Students, Volunteers and Subjects: Experiments on social preferences.

12-10 Klose, B. and Kovenock, D. Extremism Drives Out Moderation.

12-09 Buchanan, J. and Wilson, B. An Experiment on Protecting Intellectual Property.

12-08 Buchanan, J., Gjerstad, S. and Porter, D. Information Effects in Multi-Unit Dutch Auctions.

12-07 Price, C. and Sheremeta, R. Endowment Origin, Demographic Effects and Individual Preferences in Contests.

12-06 Magoa, S. and Sheremeta, R. Multi-Battle Contests: An experimental study.

12-05 Sheremeta, R. and Shields, T. Do Liars Believe? Beliefs and Other-Regarding Preferences in Sender-Receiver Games.

12-04 Sheremeta, R., Masters, W. and Cason. T. Winner-Take-All and Proportional-Prize Contests: Theory and experimental results.

12-03 Buchanan, J., Gjerstad, S. and Smith, V. There's No Place Like Home.

12-02 Corgnet, B. and Rodriguez-Lara, I. Are you a Good Employee or Simply a Good Guy? Influence Costs and Contract Design. 
12-01 Kimbrough, E. and Sheremeta, R. Side-Payments and the Costs of Conflict.

\section{1}

11-20 Cason, T., Savikhin, A. and Sheremeta, R. Behavioral Spillovers in Coordination Games.

11-19 Munro, D. and Rassenti, S. Combinatorial Clock Auctions: Price direction and performance.

11-18 Schniter, E., Sheremeta, R., and Sznycer, D. Restoring Damaged Trust with Promises, Atonement and Apology.

11-17 Brañas-Garza, P., and Proestakis, A. Self-discrimination: A field experiment on obesity.

11-16 Brañas-Garza, P., Bucheli, M., Paz Espinosa, M., and García-Muñoz, T. Moral Cleansing and Moral Licenses: Experimental evidence.

11-15 Caginalp, G., Porter, D., and Hao, L. Asset Market Reactions to News: An experimental study.

11-14 Benito, J., Branas-Garz, P., Penelope Hernandez, P., and Sanchis Llopis, J. Strategic Behavior in Schelling Dynamics: A new result and experimental evidence.

11-13 Chui, M., Porter, D., Rassenti, S. and Smith, V. The Effect of Bidding Information in Ascending Auctions.

11-12 Schniter, E., Sheremeta, R. and Shields, T. Conflicted Minds: Recalibrational emotions following trust-based interaction.

11-11 Pedro Rey-Biel, P., Sheremeta, R. and Uler, N. (Bad) Luck or (Lack of) Effort?: Comparing social sharing norms between US and Europe.

11-10 Deck, C., Porter, D., and Smith, V. Double Bubbles in Assets Markets with Multiple Generations.

11-09 Kimbrough, E., Sheremeta, R., and Shields, T. Resolving Conflicts by a Random Device.

11-08 Brañas-Garza, P., García-Muñoz, T., and Hernan, R. Cognitive effort in the Beauty Contest Game.

11-07 Grether, D., Porter, D., and Shum, M. Intimidation or Impatience? Jump Bidding in On-line Ascending Automobile Auctions.

11-06 Rietz, T., Schniter, E., Sheremeta, R., and Shields, T. Trust, Reciprocity and Rules.

11-05 Corgnet, B., Hernan-Gonzalez, R., and Rassenti, S. Real Effort, Real Leisure and Real-time Supervision: Incentives and peer pressure in virtual organizations.

11-04 Corgnet, B. and Hernán-González R. Don’t Ask Me If You Will Not Listen: The dilemma of participative decision making. 
11-03 Rietz, T., Sheremeta, R., Shields, T., and Smith, V. Transparency, Efficiency and the Distribution of Economic Welfare in Pass-Through Investment Trust Games.

11-02 Corgnet, B., Kujal, P. and Porter, D. The Effect of Reliability, Content and Timing of Public Announcements on Asset Trading Behavior.

11-01 Corgnet, B., Kujal, P. and Porter, D. Reaction to Public Information in Markets: How much does ambiguity matter?

\section{0}

10-23 Sheremeta, R. Perfect-Substitutes, Best-Shot, and Weakest-Link Contests between Groups.

10-22 Mago, S., Sheremeta, R., and Yates, A. Best-of-Three Contests: Experimental evidence.

10-21 Kimbrough, E. and Sheremeta, R. Make Him an Offer He Can't Refuse: Avoiding conflicts through side payments.

10-20 Savikhim, A. and Sheremeta, R. Visibility of Contributions and Cost of Inflation: An experiment on public goods.

10-19 Sheremeta, R. and Shields, T. Do Investors Trust or Simply Gamble?

10-18 Deck, C. and Sheremeta, R. Fight or Flight? Defending Against Sequential Attacks in the Game of Siege.

10-17 Deck, C., Lin, S. and Porter, D. Affecting Policy by Manipulating Prediction Markets: Experimental evidence.

10-16 Deck, C. and Kimbrough, E. Can Markets Save Lives? An Experimental Investigation of a Market for Organ Donations.

10-15 Deck, C., Lee, J. and Reyes, J. Personality and the Consistency of Risk Taking Behavior: Experimental evidence.

10-14 Deck, C. and Nikiforakis, N. Perfect and Imperfect Real-Time Monitoring in a Minimum-Effort Game.

10-13 Deck, C. and Gu, J. Price Increasing Competition? Experimental Evidence.

10-12 Kovenock, D., Roberson, B., and Sheremeta, R. The Attack and Defense of Weakest-Link Networks.

10-11 Wilson, B., Jaworski, T., Schurter, K. and Smyth, A. An Experimental Economic History of Whalers' Rules of Capture.

10-10 DeScioli, P. and Wilson, B. Mine and Thine: The territorial foundations of human property. 
10-09 Cason, T., Masters, W. and Sheremeta, R. Entry into Winner-Take-All and Proportional-Prize Contests: An experimental study.

10-08 Savikhin, A. and Sheremeta, R. Simultaneous Decision-Making in Competitive and Cooperative Environments.

10-07 Chowdhury, S. and Sheremeta, R. A generalized Tullock contest.

10-06 Chowdhury, S. and Sheremeta, R. The Equivalence of Contests.

10-05 Shields, T. Do Analysts Tell the Truth? Do Shareholders Listen? An Experimental Study of Analysts' Forecasts and Shareholder Reaction.

10-04 Lin, S. and Rassenti, S. Are Under- and Over-reaction the Same Matter? A Price Inertia based Account.

10-03 Lin, S. Gradual Information Diffusion and Asset Price Momentum.

10-02 Gjerstad, S. and Smith, V. Household Expenditure Cycles and Economic Cycles, 1920-2010.

10-01 Dickhaut, J., Lin, S., Porter, D. and Smith, V. Durability, Re-trading and Market Performance.

\section{9}

09-11 Hazlett, T., Porter, D., and Smith, V. Radio Spectrum and the Disruptive Clarity OF Ronald Coase.

09-10 Sheremeta, R. Expenditures and Information Disclosure in Two-Stage Political Contests.

09-09 Sheremeta, R. and Zhang, J. Can Groups Solve the Problem of Over-Bidding in Contests?

09-08 Sheremeta, R. and Zhang, J. Multi-Level Trust Game with "Insider" Communication.

09-07 Price, C. and Sheremeta, R. Endowment Effects in Contests.

09-06 Cason, T., Savikhin, A. and Sheremeta, R. Cooperation Spillovers in Coordination Games.

09-05 Sheremeta, R. Contest Design: An experimental investigation.

09-04 Sheremeta, R. Experimental Comparison of Multi-Stage and One-Stage Contests.

09-03 Smith, A., Skarbek, D., and Wilson, B. Anarchy, Groups, and Conflict: An experiment on the emergence of protective associations.

09-02 Jaworski, T. and Wilson, B. Go West Young Man: Self-selection and endogenous property rights.

09-01 Gjerstad, S. Housing Market Price Tier Movements in an Expansion and Collapse. 


\section{8}

08-09 Dickhaut, J., Houser, D., Aimone, J., Tila, D. and Johnson, C. High Stakes Behavior with Low Payoffs: Inducing preferences with Holt-Laury gambles.

08-08 Stecher, J., Shields, T. and Dickhaut, J. Generating Ambiguity in the Laboratory.

08-07 Stecher, J., Lunawat, R., Pronin, K. and Dickhaut, J. Decision Making and Trade without Probabilities.

08-06 Dickhaut, J., Lungu, O., Smith, V., Xin, B. and Rustichini, A. A Neuronal Mechanism of Choice.

08-05 Anctil, R., Dickhaut, J., Johnson, K., and Kanodia, C. Does Information Transparency Decrease Coordination Failure?

08-04 Tila, D. and Porter, D. Group Prediction in Information Markets With and Without Trading Information and Price Manipulation Incentives.

08-03 Thomas, C. and Wilson, B. Horizontal Product Differentiation in Auctions and Multilateral Negotiations.

08-02 Oprea, R., Wilson, B. and Zillante, A. War of Attrition: Evidence from a laboratory experiment on market exit.

08-01 Oprea, R., Porter, D., Hibbert, C., Hanson, R. and Tila, D. Can Manipulators Mislead Prediction Market Observers? 